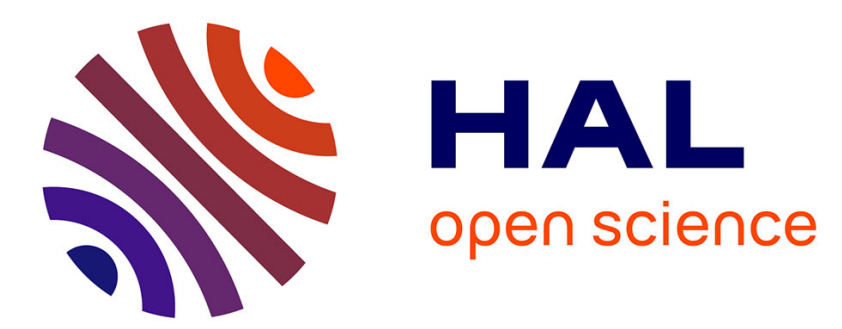

\title{
The Capability of CI-Orbitrap for Gas-Phase Analysis in Atmospheric Chemistry: A Comparison with the Cl-APi-TOF Technique
}

M. Riva, M. Bruggemann, D. Li, S. Perrier, C. George, H. Herrmann, T. Berndt

\section{To cite this version:}

M. Riva, M. Bruggemann, D. Li, S. Perrier, C. George, et al.. The Capability of CI-Orbitrap for Gas-Phase Analysis in Atmospheric Chemistry: A Comparison with the Cl-APi-TOF Technique. Analytical Chemistry, 2020, 92 (12), pp.8142-8150. 10.1021/acs.analchem.0c00111 . hal-02895039

\section{HAL Id: hal-02895039 \\ https://hal.science/hal-02895039}

Submitted on 22 Nov 2021

HAL is a multi-disciplinary open access archive for the deposit and dissemination of scientific research documents, whether they are published or not. The documents may come from teaching and research institutions in France or abroad, or from public or private research centers.
L'archive ouverte pluridisciplinaire HAL, est destinée au dépôt et à la diffusion de documents scientifiques de niveau recherche, publiés ou non, émanant des établissements d'enseignement et de recherche français ou étrangers, des laboratoires publics ou privés. 
4

5

6

7

8

9

10

\section{The capability of CI-Orbitrap for gas-phase analysis in} atmospheric chemistry:

\section{A comparison with the CI-APi-TOF technique}

M. Riva ${ }^{\dagger, *}$, M. Brüggemann ${ }^{\ddagger}$, D. Li $^{\dagger}$, S. Perrier ${ }^{\dagger}$, C. George ${ }^{\dagger}$, H. Herrmann ${ }^{\ddagger}$, T. Berndt ${ }^{\ddagger}, *$

${ }^{\dagger}$ Univ Lyon, Université Claude Bernard Lyon 1, CNRS, IRCELYON, F-69626, Villeurbanne, France.

${ }^{\ddagger}$ Leibniz Institute for Tropospheric Research (TROPOS), Atmospheric Chemistry Department (ACD),

Permoserstr. 15, 04318 Leipzig (Germany) 


\section{Abstract}

12 Chemical ionization Orbitrap mass spectrometry (CI-Orbitrap) represents a promising new technique

13 for gas-phase analysis in analytical and atmospheric chemistries mainly due to its very high mass

14 resolving power. In this work, we performed the first side-by-side comparison between a CI-Orbitrap and the widely used atmospheric pressure interface time-of-flight mass spectrometry (CI-APi-TOF) using two different chemical ionization methods, i.e., acetate-ion-based $\left(\mathrm{CH}_{3} \mathrm{COO}^{-}\right)$and aminium-ionbased $\left(n-\mathrm{C}_{3} \mathrm{H}_{7} \mathrm{NH}_{3}{ }^{+}\right)$schemes. The capability of the CI-Orbitrap at accurately measuring low concentrations of gaseous species formed from the oxidation of $\alpha$-pinene was explored. Although this study reveals a lack of linearity of the CI-Orbitrap when measuring product ions at very low concentrations $\left(<1 \times 10^{6}\right.$ molecules $\left.\mathrm{cm}^{-3}\right)$, very good agreement between both techniques can be

21 achieved by applying a newly developed linearity correction. It is experimentally shown that the correction function is independent of the reagent ion used. Thus, accurate quantification of organic compounds at concentrations as low as $1 \times 10^{5}$ molecules $\mathrm{cm}^{-3}$ by the CI-Orbitrap can be achieved.

24 Finally, by means of tandem mass spectrometry, the unique capability of the Orbitrap allows the direct

25 determination of the binding energy of cluster ions between analyte and reagent ions, that is needed

26 for the assessment of a chosen ionization scheme. 


\section{Introduction}

Biogenic and anthropogenic activities constantly release a wide variety of volatile organic compounds (VOCs) into the atmosphere. ${ }^{1,2}$ Once emitted, VOC are rapidly oxidized to form oxidized VOCs (OVOCs) spanning a broad range of chemical formulas, and, thus, volatilities. ${ }^{1,3,4}$ As a result, organic compounds play a key role in the formation of atmospheric aerosol by either condensing onto preexisting aerosol particles or by forming new particles. ${ }^{1,2,5,6}$ VOC emissions strongly impact atmospheric chemistry, human health, and Earth's climate. More specifically, a critical starting point in new particle formation (NPF) and growth is the generation of highly oxygenated multifunctional organic molecules (HOMs) through a process usually referred to as autoxidation. ${ }^{7-9}$ In the course of the autoxidation process, peroxy $\left(\mathrm{RO}_{2}\right)$ radicals, formed via the oxidation of a VOC, undergo an intramolecular hydrogen shift reaction, $\mathrm{ROO} \rightarrow \mathrm{QOOH}$, followed by the addition of molecular oxygen resulting in the formation of a new $\mathrm{R}^{\prime} \mathrm{O}_{2}$ radical: $\mathrm{QOOH}+\mathrm{O}_{2} \rightarrow \mathrm{OOQOOH}\left(\mathrm{R}^{\prime} \mathrm{O}_{2}\right)$ ("Q" stands for the organic group "R" after interamolecular $\mathrm{H}$ shift). This chain reaction can be repeated, yielding a broad diversity of products depending on the $\mathrm{RO}_{2}$ radical termination steps. ${ }^{8,10-12}$ As a result, HOMs can be formed efficiently at high enough yields to consider them as a significant source of condensing, or, in certain cases, even nucleating, organic components. ${ }^{6-8,13-15}$ Finally, $\mathrm{RO}_{2}$ chemistry not only controls the formation of HOMs and NPF but also impacts the production of secondary pollutants including $\mathrm{O}_{3}$ and $\mathrm{NO}_{2}{ }^{16}$ While in the last decade major breakthroughs have been achieved within the field of atmospheric oxidation processes and new particle formation, ${ }^{6-8,17}$ a complete understanding of how VOC oxidation products contribute to new particle and SOA formation remains poorly constrained. Indeed, gas-phase oxidation processes of biogenic and anthropogenic VOCs yield a number of oxidized products resulting in extremely complex mixture of oxygenated VOCs (OVOCs). These span a wide range of chemical formulas, structures, and physicochemical properties and pose a critical challenge in detecting, quantifying, and characterizing key atmospheric species including $\mathrm{RO}_{2}$ radicals and HOMs.

Mass spectrometric techniques have recently made enormous improvements in detecting and quantifying gaseous oxygenated species. ${ }^{18-20}$ In particular, chemical ionization mass spectrometry (CIMS) has emerged as a prevailing tool due to its very low detection limits, good sensitivity, and 
capability of measuring a wide variety of gaseous organic and inorganic species. ${ }^{8,10,10,21}$ Chemical ionization (CI) is a soft ionization technique where the analyte is ionized via a clustering process with the reagent ion with minimal fragmentation or via proton transfer processes. ${ }^{21-24}$ As part of the rapid development, multiple reagent ion schemes have been tested over the last few years. Due to the improvements in sensitivity and/or selectivity, a wide variety of oxygenated species, including $\mathrm{RO}_{2}$ radicals and stabilized Criegee intermediates, can now be directly analyzed. ${ }^{10,11,19,20,25,26}$ However, most of the CI mass spectrometers offer a rather limited mass resolving power (i.e., from 2000 to 14 000), hindering yet a complete and unambiguous identification of the compounds of interest. Consequently, the presence of multiple overlapping ions leads to significant uncertainties that can only be partly resolved by computational techniques. To overcome these limitations, we have recently coupled a high-resolution mass spectrometer (Orbitrap) with a CI source. ${ }^{30}$ The CI-Orbitrap combines the benefits of soft atmospheric pressure ionization with a unique mass resolving power $(R \geq 140000$ at $m / z$ 200). In our first study we demonstrated the applicability of this new analytical method and evaluated its ability in detecting and characterizing OVOCs formed during the oxidation of two monoterpenes using nitrate-based $\left(\mathrm{NO}_{3}{ }^{-}\right) \mathrm{CI} .{ }^{30}$ Nonetheless, a direct comparison with the widely used atmospheric pressure interface time-of-flight mass spectrometry (CI-APi-TOF) has not been performed hitherto. Hence, the sensitivity as well as the linearity of the CI-Orbitrap with different reagent ions operated in the positive or negative mode need to be determined and compared to those of the CI-APi-TOF.

Within the present study, we performed the first side-by-side comparison between a CIOrbitrap and a CI-APi-TOF applying two different chemical ionization schemes i.e., the acetate-ionbased $\left(\mathrm{CH}_{3} \mathrm{COO}^{-}\right)^{10,11}$ and the aminium-ion-based $\left(\mathrm{n}_{-} \mathrm{C}_{3} \mathrm{H}_{7} \mathrm{NH}_{3}{ }^{+}\right)^{11}$ product ionization. Unlike our initial study, we performed our experiments in a free-jet system designed to probe the early stage of a given reaction. A very short residence time was used as well as very low reactant conversion. As a result, $\mathrm{RO}_{2}$ radicals are the main products and experiments are performed within atmospheric reaction conditions, where bimolecular steps are only important for relatively high $\mathrm{RO}_{2} / \mathrm{HO}_{2}$ levels or in the presence of high enough concentrations of additives (e.g., NO). Hence, very low concentrations of $\mathrm{RO}_{2}$ radicals and OVOCs are produced from the ozone and $\mathrm{OH}$ radical initiated oxidation of $\alpha$-pinene 
in order to ascertain the benefit and the limitation of the CI-Orbitrap. We also explored the potential of the CI-Orbitrap in evaluating the binding energies of $\mathrm{RO}_{2}$ radicals and OVOCs clustered with acetate and aminium $\left(\mathrm{n}-\mathrm{C}_{3} \mathrm{H}_{7} \mathrm{NH}_{3}{ }^{+}\right)$by means of tandem mass spectral analyses $\left(\mathrm{MS}^{2}\right)$.

\section{EXPERIMENTAL SECTION}

Ozonolysis and $\mathrm{OH}$ radical initiated oxidation of $\alpha$-pinene $\left(\mathrm{C}_{10} \mathrm{H}_{16}\right)$ were performed under dry conditions $(\mathrm{RH}<0.1 \%)$ in air using a free-jet flow system at a temperature of $297 \pm 1 \mathrm{~K}$ and atmospheric pressure. ${ }^{10,11}$ This flow system allows the investigation of VOC oxidation under atmospheric conditions with negligible wall effects and a reaction time of $7.9 \mathrm{~s}$. Ozone produced from a low-pressure mercury lamp or isopropyl nitrite (IPN) was premixed with air (5 L/min (STP) ) and injected through the inner tube into the main gas stream (95 L/min (STP)) containing $\alpha$-pinene diluted in air. Ozonolysis experiments (dark reaction) were performed in the absence of an $\mathrm{OH}$ scavenger, i.e., the in-situ $\mathrm{OH}$ radical formation from ozonolysis led to a combined $\mathrm{O}_{3} / \mathrm{OH}+\alpha$-pinene reaction. In the pure OH experiments based on IPN photolysis, 8 NARVA 36W Blacklight Blue lamps were used for illuminating the flow system. All gas flows were set by means of calibrated gas flow controllers (MKS 1259/1179). The concentration of $\alpha$-pinene was maintained at $5.0 \times 10^{11}$ molecules $\mathrm{cm}^{-3}$, while ozone and IPN were ramping up from $2.5 \times 10^{10}$ to $5.6 \times 10^{11}$ and from $1.7 \times 10^{10}$ to $6.7 \times 10^{11}$ molecules $\mathrm{cm}^{-}$ ${ }^{3}$, respectively.

The chemical composition of the oxygenated products was retrieved in real time by a QExactive Orbitrap Plus mass spectrometer (Thermo Scientific) and a chemical ionization - atmospheric pressure interface - time-of-flight mass spectrometer (CI-APi-TOF, Tofwerk AG). Both instruments have been described elsewhere and were equipped with a similar Eisele-type inlet. ${ }^{21,30-33}$ While the CI inlet mounted on the APi-TOF is manufactured by Airmodus (Finland), the CI inlet installed on the Orbitrap is a home-built version with minor modifications regarding to the commercially available inlet (i.e., dimensions of the drift tube and specific flange, see for more details ref. ${ }^{30}$ ). The sample flow rate for both instruments was set at $\sim 10 \mathrm{~L} / \mathrm{min}(\mathrm{STP})$. Protonated n-propylamine $\left(\mathrm{n}-\mathrm{C}_{3} \mathrm{H}_{7} \mathrm{NH}_{3}{ }^{+}\right)$or acetate $\left(\mathrm{CH}_{3} \mathrm{COO}^{-}\right)$ions were produced using an X-ray source or an Am-241 source for the Orbitrap and the APi-TOF, respectively. In the ion-molecule-reaction (IMR) zone, the reagent ions from a clean sheath nitrogen flow were guided into the concentric sample flow by an electrical field without 
111 turbulent mixing of both streams. The residence time within the IMR zone was in the range of $200-$

$112300 \mathrm{~ms}$ in both instruments.

113 The reagent ions were $\left(\mathrm{CH}_{3} \mathrm{COOH}\right)_{n}-\mathrm{CH}_{3} \mathrm{COO}^{-}(\mathrm{n}=0,1)$ and $\left(\mathrm{n}^{-} \mathrm{C}_{3} \mathrm{H}_{7} \mathrm{NH}_{2}\right)_{\mathrm{m}}-\mathrm{n}-\mathrm{C}_{3} \mathrm{H}_{7} \mathrm{NH}_{3}{ }^{+}(\mathrm{m}$

$114=0,1)$ in the negative and positive mode, respectively. $\mathrm{RO}_{2}$ radicals as well as closed-shell products, 115 called "prod" for all together, were detected as clusters with the respective reagent ions according to 116 the following reactions (1) and (2):

117

$$
\left(\mathrm{CH}_{3} \mathrm{COOH}\right)_{\mathrm{n}}-\mathrm{CH}_{3} \mathrm{COO}^{-}+\text {prod } \rightarrow(\text { prod })-\mathrm{CH}_{3} \mathrm{COO}^{-}+\left(\mathrm{CH}_{3} \mathrm{COOH}\right)_{\mathrm{n}}(\mathrm{n}=0,1)
$$

$\left(\mathrm{n}-\mathrm{C}_{3} \mathrm{H}_{7} \mathrm{NH}_{2}\right)_{\mathrm{m}}-\mathrm{n}-\mathrm{C}_{3} \mathrm{H}_{7} \mathrm{NH}_{3}{ }^{+}+$prod $\rightarrow($ prod $)-\mathrm{n}-\mathrm{C}_{3} \mathrm{H}_{7} \mathrm{NH}_{3}{ }^{+}+\left(\mathrm{n}-\mathrm{C}_{3} \mathrm{H}_{7} \mathrm{NH}_{2}\right)_{\mathrm{m}}(\mathrm{m}=0,1)$

121 It is important to mention that the absolute calibration of the detected oxygenated products is impossible due to a lack of authentic reference substances for $\mathrm{RO}_{2}$ radicals and the majority of closedshell products. Thus, the product signals of both mass spectrometers were normalized to the sum of the reagent ions, i.e., $\Sigma\left[\left(\mathrm{CH}_{3} \mathrm{COOH}\right)_{n}-\mathrm{CH}_{3} \mathrm{COO}^{-}(\mathrm{n}=0,1)\right]$ or $\Sigma\left[\left(\mathrm{n}^{-} \mathrm{C}_{3} \mathrm{H}_{7} \mathrm{NH}_{2}\right)_{\mathrm{m}}-\mathrm{n}-\mathrm{C}_{3} \mathrm{H}_{7} \mathrm{NH}_{3}{ }^{+}(\mathrm{m}=\right.$ 0,1)]. The resulting normalized signals were used for the comparison in order to evaluate the performance of both techniques.

However, the lower end value of the calibration factor $\mathrm{f}$ can be calculated considering the ionmolecule reaction within the CI-inlet, $\mathrm{f}=1 /\left(\mathrm{k} \times \mathrm{t} \times \mathrm{f}_{\text {inlet }}\right),{ }^{34}$ where $\mathrm{k}$ is the rate coefficient of the ionmolecule reaction, $t$ the reaction time and $f_{\text {inlet }}$ corresponds to the "prod" loss in the sampling tube.

130 Diffusion loss of the $\mathrm{RO}_{2}$ radicals and OVOCs in the sampling lines to the CI-APi-TOF and the CI-

131 Orbitrap were calculated to be $12 \%$ and $38 \%$, respectively, assuming diffusion-controlled wall 132 losses. ${ }^{10}$ Taking into account this diffusion loss, $\mathrm{f}_{\text {inlet }}=0.88$, and a reaction time of the ion-molecule 133 reaction $\mathrm{t}=0.2-0.3 \mathrm{~s}$ (which is similar for both instruments), a calibration of $\mathrm{f}_{\text {calc }}=(1.3-2.8) \times 10^{9}$ 134 molecules $\mathrm{cm}^{-3}$ can be calculated. It should be mentioned that using the only reliable absolute 135 calibration technique (i.e., sulfuric acid) a calibration factor of $\mathrm{f}_{\mathrm{H} 2 \mathrm{SO} 4 \text {,exp }}=1.85 \times 10^{9}$ molecules cm ${ }^{-3}$ 136 was determined in previous experiments. This value is in good agreement with the range of $f_{\text {calc }}$ The 
uncertainty of the lower end "prod" concentrations determined according to equation (1) or (2) is assumed to be not higher than a factor of two due to the expected uncertainty of the used calibration

140 factor $\mathrm{f}_{\mathrm{H} 2 \mathrm{SO} 4 \text {,exp }}=1.85 \times 10^{9}$ molecules $\mathrm{cm}^{-3}$, and possible inaccuracy connected with the duty cycle 141 correction. Therefore, only lower limit product concentrations are available based on this calculated 142 calibration factor.

Duty cycle correction was applied for the APi-TOF data in order to account for the $\mathrm{m} / \mathrm{z}$

144 discrimination during the ion extraction. ${ }^{10,24,35}$ In the case of the CI-Orbitrap, for each experiment, the

145 ion transmission was evaluated by comparing the loss of the number of charges of the reagent ions 146 with the increase of the number of charges of all the ions within the $m / z 200-600 \mathrm{Th}$. This simple 147 method provides a rough estimate of the ion transmission for the compounds of interest relative to the 148 reagent ions. As a result, a factor of 2 was applied to correct for the lower ion transmission of the 149 reagent ions in order to determine the normalized signals. In addition, we further evaluated the ion transmission of the Q Exactive Orbitrap in the $\mathrm{m} / z 53$ - 800 Th using the depletion method described by Heinritzi et al. ${ }^{36}$ This method takes into consideration losses within the inlet as well as the different ion optics and C-Trap (see Figure S1). In short, 4 different perfluorinated acids were introduced into the mass analyzer in order to deplete the reagent ions. As a result, the relative transmission efficiency can be obtained by comparing the decrease of signal strength of the reagent ions with the rising signals from the perfluorinated acids at larger masses (see supplementary information for more details). The relative ion transmission was only determined for the Q-Exactive Orbitrap using nitrate-ion based chemistry. It should be pointed out that the depletion method leads to significantly different results for the ion transmission of a mass spectrometer than absolute calibration methods. ${ }^{7,36-38}$ Nevertheless, the results of the depletion method provide a first insight into the ion transmission of a Q Exactive Orbitrap. negative mode (i.e., $\mathrm{CH}_{3} \mathrm{COO}^{-}$) and connected to the free-jet flow system. The Q Exactive Orbitrap

163 (Orbitrap-IRCELYON) was solely used in negative mode $\left(\mathrm{NO}_{3}^{-}\right)$to determine the ion transmission 164 and to developed the linearity correction. Both instruments were operated using the same settings and were run in full scan mode with a high mass resolving power of 140000 (at $\mathrm{m} / \mathrm{z} 200 \mathrm{Th}$ ), allowing an 
166 identification of a wide variety of species. The instruments were operated in negative or positive

167 mode, scanning from $\mathrm{m} / \mathrm{z}, 50$ to $750 \mathrm{Th}$ with an automatic gain control (AGC) target of $1 \times 10^{5}$ 168 charges, a maximum injection time of $1 \mathrm{~s}$, resulting in a scan rate of $0.2 \mathrm{scans} / \mathrm{s}$. Spectra were 169 averaged of 5 microscans ( 1 microscan corresponding to 1 ion injection). The stacked-ring ion guide 170 (or S-Lens) is a radio frequency (RF) device efficiently capturing and focusing the ions into a tight 171 beam. As previously described it contains a series of electrodes where voltages are applied in order to 172 focus the ions. The S-lens level was maintained at $60 \%$, to maximize ion transmission and the limit of 173 detection. The C-Trap consist of a RF-based ion collecting trap (Figure S1), which is automatically 174 controlled by the AGC (automatic gain control) in order to prevent space-charge effects. In order to 175 evaluate the impact of the number of charges collected in the C-trap, the AGC target of the Orbitrap176 Tropos instrument was scanned from $5 \times 10^{4}$ to $1 \times 10^{6}$ charges. External mass calibrations were 177 performed prior to the experiments by injecting a $2 \mathrm{mM}$ sodium acetate solution using an electrospray 178 ionization source. This procedure provided a suite of negative and positive adduct ions in the desired 179 mass range of $m / z 59-700$ Th. Tandem mass spectral $\left(\mathrm{MS}^{2}\right)$ analyses were performed by ramping up 180 the normalized collision energy (NCE) from $1-7 \mathrm{eV}$ (i.e., normalized to singly charged ions at $\mathrm{m} / \mathrm{z}$ 181 500). Thus, to retrieve the collision energy (CE) encountered by ions at any given $\mathrm{m} / \mathrm{z}$ ratio within the 182 higher-energy collision dissociation (HCD) cell, the CE can be calculated as follows: $\mathrm{CE}=(\mathrm{m} / \mathrm{z} / \mathrm{500})$ $183 \mathrm{x}$ NCE $\mathrm{x} f$, where $\mathrm{f}$ stands for the number of charges of the ion. To ensure an optimal detection of the 184 product ions, the mass spectra obtained using the CI-APi-TOF and the CI-Orbitrap were averaged over 18510 minutes each. A time resolution of 5 min was used for the $\mathrm{MS}^{2}$ analyses conducted by the Orbitrap. 186 The high-resolution Orbitrap data were analyzed by XCalibur 4.1 (Thermo Scientific) software 187 package to determine accurate composition and the abundance of the compounds of interest. Peak 188 fitting of the CI-APi-TOF data was performed by means of the Matlab-based toftools software. ${ }^{37}$

\section{RESULTS AND DISCUSSION}

191 Characterization of the CI-Orbitrap. Despite the wealth of studies using the Orbitrap technique,

192 little is known about the capability of the Orbitrap in measuring compounds on-line at low 193 concentrations. For example it has been reported that the Orbitrap can provide a non-linear response, 
194 potentially impacting isotope ratios, determination and the quantification of compounds present at 195 extremely low concentrations. ${ }^{39}$ In view of these findings available from literature, we evaluated the 196 performance of the CI-Orbitrap by comparing the measured vs. the theoretical isotopic intensities 197 using product ions analyzed by the Orbitrap-Tropos using protonated n-propylamine $\left(n-\mathrm{C}_{3} \mathrm{H}_{7} \mathrm{NH}_{3}{ }^{+}\right)$ 198 and acetate $\left(\mathrm{CH}_{3} \mathrm{COO}^{-}\right)$. To further estimate the impact of different reagent ions, results from our 199 former study performed with the Orbitrap-IRCELYON using nitrate-ion based chemistry ${ }^{30}$ are also 200 compared here. In both cases, OVOCs were continuously generated in the flow tube from either the 201 ozonolysis and/or $\mathrm{OH}$ radical initiated oxidation of $\alpha$-pinene. Hence, the abundance of the main 202 OVOCs (e.g., $\mathrm{C}_{10} \mathrm{H}_{14,16} \mathrm{O}_{\mathrm{x}} ; \mathrm{C}_{20} \mathrm{H}_{30,32} \mathrm{O}_{\mathrm{x}}$ ) and $\mathrm{RO}_{2}$ radicals (e.g., $\mathrm{C}_{10} \mathrm{H}_{15,17} \mathrm{O}_{\mathrm{x}}$ ) at nominal masses $\mathrm{M}$, (M $203+1)$ and $(\mathrm{M}+2)$, corresponding to their ${ }^{13} \mathrm{C}$ atom and ${ }^{18} \mathrm{O}$ atom fraction, were measured to cover a 204 wide range of normalized product signals in the range of $5 \times 10^{-7}$ to $5 \times 10^{-2}$. Signal intensities 205 reported in Figure 1A were obtained with an AGC target of $1 \times 10^{5}$ charges. As depicted in Figure 1A, 206 when the ratio is equal to 1.0 for normalized signal $>\sim 4 \times 10^{-4}$ to $\left(\sim 1 \times 10^{6}\right.$ molecules $\left.\mathrm{cm}^{-3}\right)$, the 207 Orbitrap is providing a linear measure of the ion intensity. However, this ratio dropped significantly 208 for normalized signals below $\sim 4 \times 10^{-4}$. Such a situation occurs when the ion intensity is close to the 209 instrumental threshold, i.e., by using standard settings the Orbitrap mass analyzer records only signals 210 if $\mathrm{S} / \mathrm{N}>1.3$. The ion signals below this threshold are treated as undetected by the acquisition software. 211 Due to the statistics, peaks with an average $\mathrm{S} / \mathrm{N}=1.5$ for example will appear above this threshold 212 only in a limited amount of cases reducing the resulting peak intensity. ${ }^{40}$ As a result, for a normalized 213 signal smaller than $1 \times 10^{-5}$, the CI-Orbitrap only detects $5-10 \%$ of the "true ion number 214 distribution". That means, using the instrumental parameters and the calibration factor employed here $215\left(1.85 \times 10^{9}\right.$ molecules $\left.\mathrm{cm}^{-3}\right)$ the limit of quantification (LoQ, corresponding to lowest normalized 216 signal observed within the linear range) of the Orbitrap was evaluated to be $\sim 1 \times 10^{6}$ molecules $\mathrm{cm}^{-3}$ 217 at a 10-minute integration time. It is worth pointing out that the limit of detection (LoD, corresponding 218 to the lowest normalized signal observed) is likely one or two orders of magnitude lower than the LoQ 219 but due to the lack of linearity accurate numbers cannot be directly provided. By adjusting the AGC 220 target the linear range can be shifted towards lower ion concentrations as shown in Figure 1B. This 221 can be explained by larger number of ions trapped within the C-trap prior to the Orbitrap scan 
resulting in more ions entering the Orbitrap mass analyzer. This leads to an enhanced S/N ratio and 223 better statistics. Hence, we have evaluated the impact of the AGC target (scanned from $5 \times 10^{4}$ to $1 \mathrm{x}$ $10^{6}$ charges) on the linearity and found that by optimizing the AGC target, the LoQ of the CI-Orbitrap is anticipated to be greatly extended. However, as most of our previous experiments were performed using an AGC target of $1 \times 10^{5}$ charges, we kept this setting to perform the side-by-side comparison. Comparison CI-Orbitrap vs CI-APi-TOF. To evaluate the performance of the CI-Orbitrap compared to the widely used CI-APi-TOF technique we directly performed side-by-side experiments. Both instruments, equipped with a similar type of inlet originally designed by Eisele et al. ${ }^{31}$ and running with the same reagent ion, sampled concurrently $\mathrm{RO}_{2}$ radicals as well as OVOCs produced under well-controlled reaction conditions. We focused on the detection of $\mathrm{RO}_{2}$ radicals produced from the oxidation of $\alpha$-pinene. Using acetate and aminium $\left(n-\mathrm{C}_{3} \mathrm{H}_{7} \mathrm{NH}_{3}{ }^{+}\right)$as the reagent ions, the main $\mathrm{RO}_{2}$ radicals from $\alpha$-pinene oxidation, HO- $\mathrm{C}_{10} \mathrm{H}_{16}\left(\mathrm{O}_{2}\right)_{\alpha} \mathrm{O}_{2}(\alpha=0,1,2)$, were detected by means of the CI234 Orbitrap, in line with the findings of the CI-APi-TOF. ${ }^{24,30,35}$ As depicted in Figures 2 and S2, the mass resolving power of the Orbitrap can accurately distinguish the different species, which is often impossible with typical TOF mass analyzers. To further illustrate the difference, we have directly compared ion signals measured by the CI-Orbitrap and by the CI-APi-TOF equipped with a high resolution mass analyzer (HR-TOF, resolution 3000) (Figure 2).

Figure 3 shows the results of the $\mathrm{OH}$ radical-initiated oxidation of $\alpha$-pinene. The $\mathrm{OH}$ radicals were generated by isopropyl nitrite (IPN) photolysis. The formation of the additional $\mathrm{RO}_{2}$ radical HO$\mathrm{C}_{10} \mathrm{H}_{15}(\mathrm{OH})\left(\mathrm{O}_{2}\right) \mathrm{O}_{2}$ can be explained by the reaction of $\mathrm{HO}-\mathrm{C}_{10} \mathrm{H}_{16}\left(\mathrm{O}_{2}\right)_{2} \mathrm{O}_{2}$ with $\mathrm{NO}$ and subsequent radical isomerization as discussed in a former study. ${ }^{35} \mathrm{NO}$ is formed from the IPN photolysis. In addition to the $\mathrm{RO}_{2}$ radicals, also closed-shell products were detected including carbonyls and organic nitrates produced from the $\mathrm{RO}_{2}+\mathrm{NO}$ reactions. ${ }^{16}$ Lastly, products arising from other bimolecular $\mathrm{RO}_{2}$ reactions were not detected or were below the detection limit under the selected experimental conditions due to the relatively low $\mathrm{RO}_{2}$ radical concentrations $<10^{8}$ molecules $\mathrm{cm}^{-3}$ and the very 247 short reaction time of $7.9 \mathrm{~s}$.

As shown in Figure 3, for uncorrected normalized intensities above $(2-3) \times 10^{-4}$ 249 (corresponding to $\sim(4-6) \times 10^{5}$ molecules $\mathrm{cm}^{-3}$ ) both techniques are in very good agreement. The lack 
of linearity hampers the Orbitrap, unlike the APi-TOF, to accurately measure lower concentrations.

251 However, this lack of linearity appears to be independent of the instrument and the type of reagent 252 ions (Figure 1A). This behavior indicates that this instrumental limitation can be overcome in order to 253 retrieve the "correct" signal strength for peaks with lowest signal intensity. Indeed, using all 254 measurements from multiple experiments and reagent ions, a function named "sigmoidal correction 255 function" based on a fitting algorithm using a characteristic sigmoidal shape can be determined. 256 Therefore, raw normalized signals (corrected for sampling losses) measured with the CI-Orbitrap were 257 further corrected using the "sigmoidal correction function", see also Figure 1. By applying this 258 method, all the data were corrected (open markers), which greatly helps maintaining the good 259 agreement between both techniques (Figure 3). However, for uncorrected signal intensities below a 260 threshold of $5 \times 10^{-6}-1 \times 10^{-5}$ this approach results in an overestimation of the ion concentrations as 261 the signal is likely very close to the noise level of the instrument. As a result, such data points were 262 not included in Figures 3, 4, S3 and S4. While the APi-TOF can further help correcting this lack of 263 linearity we preferred to propose a method based only on the signal acquired by the Orbitrap. Hence, 264 the reported LoD is likely an upper limit and might be even pushed further with appropriate and collocated instrumentations.

Overall, product signals measured by CI-Orbitrap and the CI-APi-TOF are mostly within a factor of 2 (Figure 5) providing a good agreement between these two analytical techniques for 268 corrected normalized signal intensity ranging from $\sim 5 \times 10^{-5}$ to $1 \times 10^{-2}$ (corresponding to $\sim 1 \times 10^{5}$ to $2692 \times 10^{7}$ molecules $\mathrm{cm}^{-3}$ ). Exception are the measurements of highly oxidized products using acetate 270 ionization. The reason for that is not clear at the moment. It is worth pointing out that the positive 271 mode measurements were less impacted by the lack of linearity compared to negative mode 272 measurements. This is explained by the fact that at a given product concentration, the resulting ion 273 intensity measured by aminium $\left(\mathrm{n}_{-} \mathrm{C}_{3} \mathrm{H}_{7} \mathrm{NH}_{3}{ }^{+}\right)$ionization is much greater than for acetate ionization. In 274 the case of the highest oxidized $\mathrm{RO}_{2}$ radicals, i.e., $\mathrm{HO}-\mathrm{C}_{10} \mathrm{H}_{16}\left(\mathrm{O}_{2}\right)_{2} \mathrm{O}_{2}$ and $\mathrm{HO}-\mathrm{C}_{10} \mathrm{H}_{15}(\mathrm{OH})\left(\mathrm{O}_{2}\right) \mathrm{O}_{2}$ 275 bearing $-\mathrm{OH}$ and $-\mathrm{OOH}$ moieties, the obtained corrected signal intensities are almost identical within a 276 factor of two applying either acetate or aminium $\left(n-\mathrm{C}_{3} \mathrm{H}_{7} \mathrm{NH}_{3}{ }^{+}\right)$for product ionization. This fact is 277 obviously due to strong binding of these $\mathrm{RO}_{2}$ radicals to both reagent ions. Thus, a near-maximum 
278 detection sensitivity can be expected for these reagent ions. ${ }^{41,42}$ On the other hand, for the less oxidized $279 \mathrm{RO}_{2}$ radicals $\mathrm{HO}-\mathrm{C}_{10} \mathrm{H}_{16} \mathrm{O}_{2}$ and $\mathrm{HO}-\mathrm{C}_{10} \mathrm{H}_{16}\left(\mathrm{O}_{2}\right) \mathrm{O}_{2}$ the detection sensitivity based on aminium (n$280 \mathrm{C}_{3} \mathrm{H}_{7} \mathrm{NH}_{3}{ }^{+}$) ionization is definitely higher compared to acetate ionization, i.e., by a factor of $500-$ 2811000 in the case of $\mathrm{HO}-\mathrm{C}_{10} \mathrm{H}_{16} \mathrm{O}_{2}{ }^{42}$

Ozonolysis experiments in the absence of an $\mathrm{OH}$ scavenger were conducted in order to 283 generate a larger variety of products, mainly $\mathrm{RO}_{2}$ radicals, formed from the simultaneous ozone and $284 \mathrm{OH}$ radical reactions of $\alpha$-pinene. Accordingly, two types of $\mathrm{RO}_{2}$ radicals have been formed, i.e., the 285 ozonolysis-derived $\mathrm{RO}_{2}$ radicals $\mathrm{O}, \mathrm{O}-\mathrm{C}_{10} \mathrm{H}_{15}\left(\mathrm{O}_{2}\right)_{\mathrm{x}} \mathrm{O}_{2}(\mathrm{x}=0,1,2,3)$ and the $\mathrm{OH}$-derived $\mathrm{RO}_{2}$ radicals 286 HO- $\mathrm{C}_{10} \mathrm{H}_{16}\left(\mathrm{O}_{2}\right)_{\alpha} \mathrm{O}_{2}(\alpha=0,1,2){ }^{7,35}$ Figure 4 presents the signal intensities of both types of $\mathrm{RO}_{2}$ 287 radicals measured by means of aminium $\left(n-\mathrm{C}_{3} \mathrm{H}_{7} \mathrm{NH}_{3}{ }^{+}\right)$ionization. While the agreement for the most 288 oxidized $\mathrm{RO}_{2}$ radicals is again very good, the signals of the less oxidized species $\mathrm{O}, \mathrm{O}-\mathrm{C}_{10} \mathrm{H}_{15} \mathrm{O}_{2}$ and 289 HO- $\mathrm{C}_{10} \mathrm{H}_{16} \mathrm{O}_{2}$ (Figures 3 and 4) are systematically higher using the CI-Orbitrap by a factor of two or 290 higher. In contrast, for the most oxidized $\mathrm{RO}_{2}$ the difference between the two instruments was only $29120 \%$. Such a disparity might be explained by less efficient declustering of the relatively weakly bound 292 aminium clusters of $\mathrm{O}, \mathrm{O}-\mathrm{C}_{10} \mathrm{H}_{15} \mathrm{O}_{2}$ and $\mathrm{HO}-\mathrm{C}_{10} \mathrm{H}_{16} \mathrm{O}_{2}$ in the CI-Orbitrap compared to the CI-APi-TOF. 293 This results in a more sensitive detection of the initially formed $\mathrm{RO}_{2}$ radicals with relatively low 294 oxygen content. It is important to mention that by applying the transmission curve to the CI-Orbitrap 295 data, a larger discrepancy exist between the results of both instruments, see Figure S6. This 296 discrepancy is obviously due to the different ion transmission corrections. Indeed, using the 297 parameters selected in this study the ion transmission within the Orbitrap exhibit a steep increase 298 between from $\mathrm{m} / \mathrm{z} 60$ to $300 \mathrm{Th}$ (SI). However, much more experimental effort is needed in the future 299 for a reliable determination of the ion transmission of both instruments and for different reagent ions. 300 Hence it would be possible to determine i) how good the duty cycle correction accounts for the overall 301 ion transmission of the CI-APi-TOF and ii) what is the accuracy of the depletion methods in 302 comparison to absolute calibration methods.

303 Overall, the side-by-side comparison displays a very good agreement of the results of the CI-

304 Orbitrap and the CI-APi-TOF with the exception of the lowest oxidized reaction products. By using 305 the "sigmoidal correction function", $1.85 \times 10^{9}$ molecules $\mathrm{cm}^{-3}$ as the calibration factor for an AGC 
target of $1 \times 10^{5}$ charges, the LoQ of the CI-Orbitrap can be as low as $1 \times 10^{5}$ molecules $\mathrm{cm}^{-3}$ at a 10 307 minute integration time.

308 Determination of cluster binding energy. In common CI-APi-TOF approaches, the organic molecules of interest are observed as molecular clusters with the reagent ion (e.g., with $\mathrm{CH}_{3} \mathrm{COO}^{-}$or n- $\mathrm{C}_{3} \mathrm{H}_{7} \mathrm{NH}_{3}{ }^{+}$), see also eq. (1) and (2). In order to provide an accurate quantification of the compounds 311 of interest it is essential to constrain the sensitivity of the reagent ion to OVOCs. To reach this goal, 312 characterizing any limitations when detecting the compounds of interest, including the ion-molecule 313 collision limit and the ion-molecule reaction time is critical. The proficiency of any neutral molecule 314 to bind to the reagent ion is directly linked to the binding energy of the adduct. Accordingly, a weakly bound adduct can undergo declustering, i.e., collision-induced dissociation (CID), during the flight trough the mass analyzer. Ultimately, the binding energy of the adduct and the energy of the collisions with gas molecules in the mass spectrometer will define the survival probability of the adduct ions. To constrain this parameter, procedures based on CID measurement coupled to quantum chemical methods have been proposed to investigate the behavior of adducts at different collision energies. ${ }^{43,44}$ Nonetheless, carrying out such measurements is challenging for the hundreds of different molecular ions, typically observed with a CI-APi-TOF, especially when molecular structures remain unknown and/or are highly complex. Therefore, to quantitatively constrain the effective binding energies of a wide range of OVOCs and $\mathrm{RO}_{2}$ radicals, we employed the capability of the Orbitrap analyzer to perform untargeted $\mathrm{MS}^{2}$ analyses. Hence, all ions were injected into the HCD cell, where they collide at a defined collision energy with $\mathrm{N}_{2}$ molecules. The NCE was ramped up from 1 to $7 \mathrm{eV}$. During the declustering scans, all potentials upstream the HCD cell remained identical and only the NCE within the HCD cell incremented, thereby avoiding any changes in the ion transmission of the mass spectrometer.

An example of the declustering analysis is presented in Figure 6A for a set of typical oxidation 330 products, for which the remaining fraction of individual ions is plotted as a function of the CE 331 (retrieve for each ion based on their $\mathrm{m} / \mathrm{z}$ ). Following the approach previously proposed for iodide332 based clusters, ${ }^{43-45}$ a sigmoidal fit was applied to the acquired data (Figure S7), in order to obtain the 333 following parameters: i) the collision energy at which half of the signal is removed $\left(\mathrm{CE}_{50}\right)$, and ii) the 
maximum amplitude of the sigmoidal function $\left(\mathrm{S}_{0}\right)$, corresponding to the relative signal intensity that

335 would be measured in absence of declustering processes during the transmission through the mass 336 spectrometer. In Table $\mathrm{S} 1$, the $\mathrm{CE}_{50}$ values of the $\mathrm{OH}$-derived OVOCs and $\mathrm{OH}$-derived $\mathrm{RO}_{2}$ produced 337 from the $\mathrm{OH}$ radical-initiated oxidation of $\alpha$-pinene are reported. While direct comparison with 338 quantum chemical calculations is not directly possible due to the absence of information on the studied 339 OVOCs, earlier studies indicate that the values reported in Table S1 are within a fairly good 340 agreement for binding energies determined for isoprene-derived oxidation products measured with CI341 APiTOF using protonated n-propylamine or acetate. ${ }^{41,42}$ For example, Berndt et al. ${ }^{42}$ have estimated 342 binding energies of the HPALD- $\left(\mathrm{n}-\mathrm{C}_{3} \mathrm{H}_{7} \mathrm{NH}_{3}{ }^{+}\right)$cluster $\left(\mathrm{C}_{5} \mathrm{H}_{8} \mathrm{O}_{3}\right)$ cluster and HPALD-CH $\mathrm{COO}^{-}$ 343 cluster of 28.5 and $31.9 \mathrm{kcal} \mathrm{mol}^{-1}$, respectively, which is close to the values determined for OVOCs 344 and $\mathrm{RO}_{2}$ radicals containing 3 oxygen atoms (Table $\mathrm{S} 1$ ) within this present study. Following the method proposed in former studies, ${ }^{43,44}$ we found that the maximum possible 346 transmission for each compound clustered with protonated n-propylamine $\left(n-\mathrm{C}_{3} \mathrm{H}_{7} \mathrm{NH}_{3}{ }^{+}\right)$is reached at 347 a binding energy of $\sim 35 \mathrm{kcal} \mathrm{mol}^{-1}$. This indicates that for cluster ions having a greater binding 348 energy, the stability of the adduct will be sufficient to transit through the different ion optics without 349 significant declustering losses. These results are in line with the side-by-side comparison, where the 350 largest discrepancy is observed for the lowest oxygenated species (e.g., $\mathrm{O}, \mathrm{O}-\mathrm{C}_{10} \mathrm{H}_{15} \mathrm{O}_{2} ; \mathrm{HO}-\mathrm{C}_{10} \mathrm{H}_{16} \mathrm{O}_{2}$ ), 351 i.e., the compounds with the lowest binding energy (Table S1). By optimizing the different voltages, 352 the declustering processes occurring within the APi-TOF and/or within the Orbitrap can be reduced. 353 Finally, it is interesting to note that earlier work, performing CID experiments using iodide-based 354 chemistry, determined a similar threshold, i.e., $\sim 30 \mathrm{kcal} \mathrm{mol}^{-1} .^{44}$

357 In this work, we demonstrated the capability of the CI-Orbitrap in measuring $\mathrm{RO}_{2}$ radicals as well as 358 OVOCs at atmospherically relevant concentrations and compared them to simultaneous CI-APi-TOF 359 measurements. We explored the current limitations of this new analytical technique and demonstrated 360 that these can be partially overcome through a careful determination of a sigmoidal correction 361 function. In addition, to unambiguously identify OVOCs formed in the gas phase, the analysis by 
362 means of the CI-Orbitrap is able to accurately quantify organic species at concentration down to $1 \times$

$36310^{5}$ molecules $\mathrm{cm}^{-3}$. This LoQ is $\sim$ one order of magnitude higher in comparison to the APi-TOF used 364 in this study. In addition to the much greater mass resolving power, another clear advantage over the 365 APi-TOF technique is the capability of performing $\mathrm{MS}^{2}$ analyses needed to retrieve information on the 366 chemical structure of the compounds of interest and to determine the binding energy of the clusters.

367 Overall, the combination of high-mass resolving power of the Orbitrap and high sensitivity of the 368 aminium/ammonium CI represents a powerful analytical tool that can improve our current knowledge 369 regarding the complexity of the atmospheric gaseous composition. Thus, this new technique can help 370 to answer some of the questions that so far were unable to be answered due to the pre-existing 371 instrument limitations. 

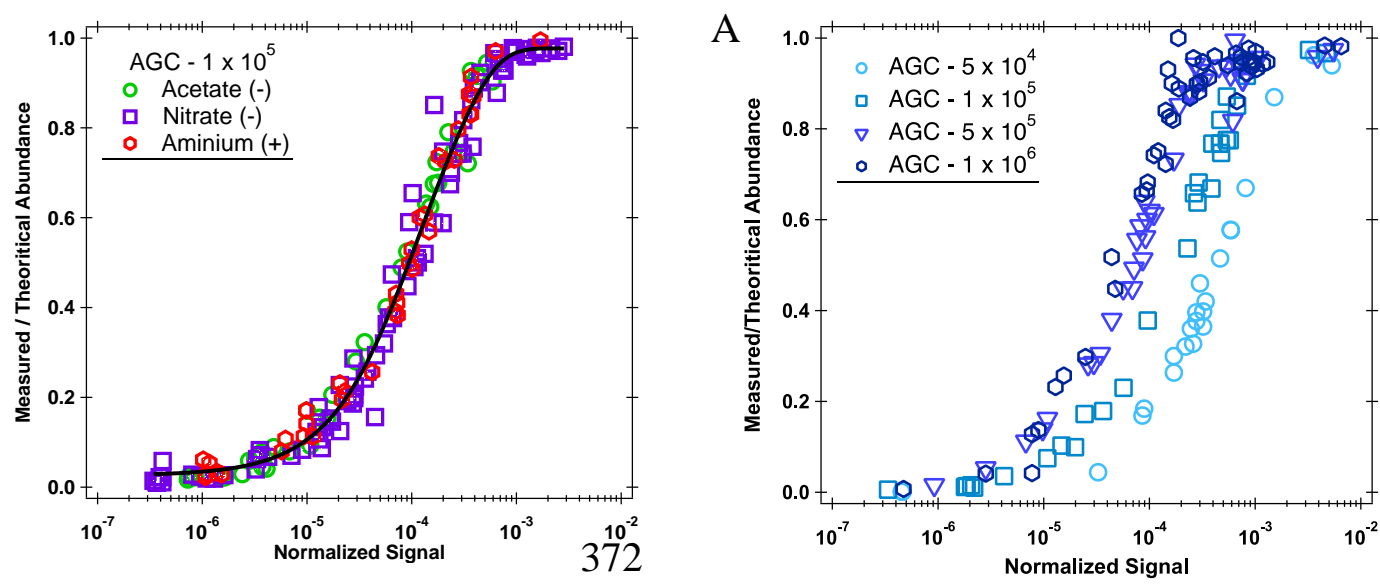

B

373 Figure 1. (A) Linearity of the Orbitrap as a function of normalized signal measured with protonated n-

374 propylamine $\left(\mathrm{n}-\mathrm{C}_{3} \mathrm{H}_{7} \mathrm{NH}_{3}{ }^{+}\right)$and acetate $\left(\mathrm{CH}_{3} \mathrm{COO}^{-}\right)$reagent ions with the Orbitrap-Tropos and nitrate-

375 ion based chemistry with the Orbitrap-IRCELYON, using identical parameter settings. All signal

376 intensities were corrected with respect to the sum of $\left(\mathrm{CH}_{3} \mathrm{COOH}\right)_{n}-\mathrm{CH}_{3} \mathrm{COO}^{-}(\mathrm{n}=0,1)$ at nominal 59

377 Th and $119 \mathrm{Th}$; to the sum of $\left(\mathrm{n}-\mathrm{C}_{3} \mathrm{H}_{7} \mathrm{NH}_{2}\right)_{\mathrm{m}}-\mathrm{n}-\mathrm{C}_{3} \mathrm{H}_{7} \mathrm{NH}_{3}{ }^{+}(\mathrm{m}=0,1)$ at nominal $60 \mathrm{Th}$ and $119 \mathrm{Th}$; and

378 to the sum of $\left(\mathrm{HNO}_{3}\right)_{\mathrm{p}}-\mathrm{NO}_{3}^{-}(\mathrm{p}=0,1,2)$ at nominal $62,125,188 \mathrm{Th}$, for the respective reagent ions.

379 The black fit is the "sigmoidal correction function" based on a sigmoidal fitting algorithm. (B) Impact

380 of the AGC target on the linearity of the CI-Orbitrap-Tropos using aminium $\left(n-\mathrm{C}_{3} \mathrm{H}_{7} \mathrm{NH}_{3}{ }^{+}\right)$as the 381 reagent ion. 
A

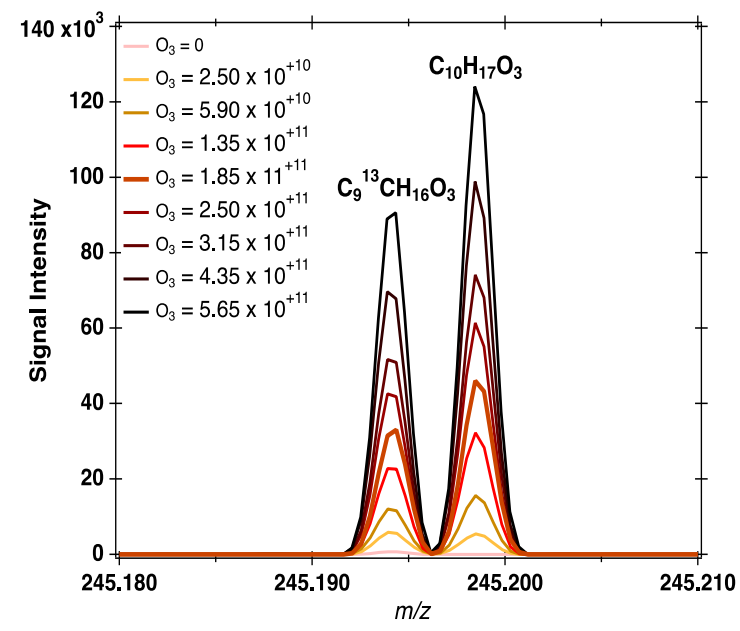

B

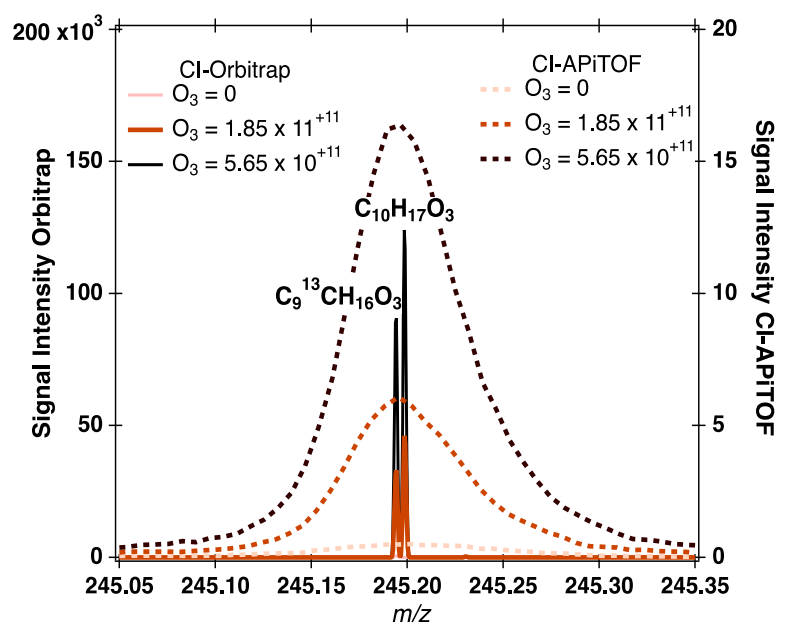

Figure 2. Mass spectra of ions at nominal $\mathrm{m} / z 245$ from the combined ozonolysis and $\mathrm{OH}$ radical reaction of $\alpha$-pinene for different reaction conditions (A) measured with the CI-Orbitrap and (B) comparison of the ion signals recorded by the CI-Orbitrap and the CI-APi-TOF. $\mathrm{C}_{9}{ }^{13} \mathrm{CH}_{16} \mathrm{O}_{3}$ represents most likely the ${ }^{13} \mathrm{C}$-isotope of pinonaldehyde and $\mathrm{C}_{10} \mathrm{H}_{17} \mathrm{O}_{3}$ the initial $\mathrm{RO}_{2}$ radical from the $\mathrm{OH}$ attack, $\mathrm{HO}-\mathrm{C}_{10} \mathrm{H}_{16} \mathrm{O}_{2}$. Concentrations are given in molecules $\mathrm{cm}^{-3}$. 


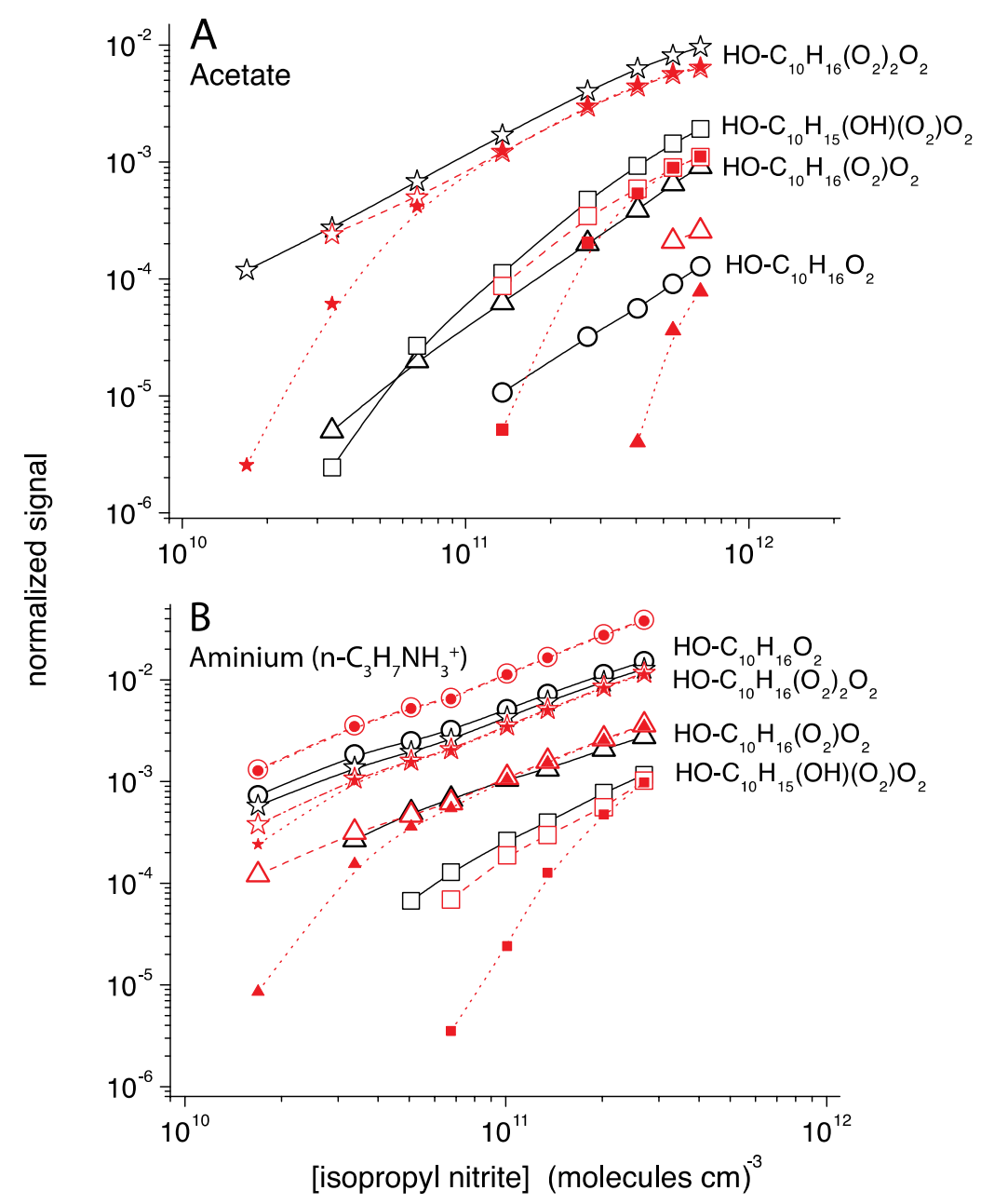

391 Figure 3. Normalized signals of $\mathrm{RO}_{2}$ radicals produced from the $\mathrm{OH}$ radical-initiated oxidation of $\alpha$ 392 pinene as a function of initial IPN concentration measured by the CI-APi-TOF (black) and the CI393 Orbitrap (red). OH radicals have been formed via IPN photolysis. Full and open markers in red 394 correspond to raw and corrected (using the sigmoidal correction function) signals measured with the 395 Orbitrap, respectively. (A) Acetate and (B) aminium $\left(n-\mathrm{C}_{3} \mathrm{H}_{7} \mathrm{NH}_{3}{ }^{+}\right)$served as the reagent ion for 396 otherwise identical reaction conditions in both cases. 


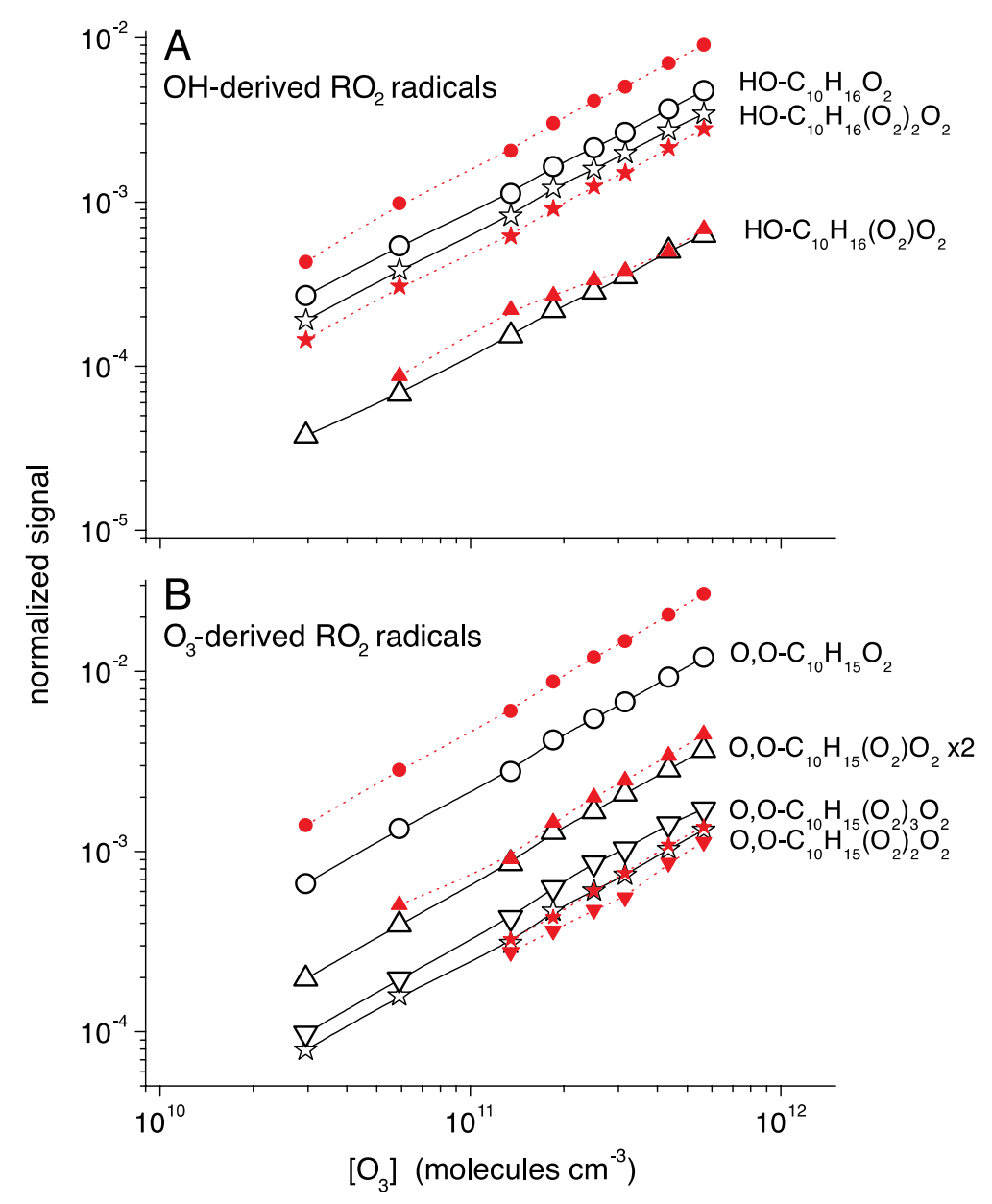

400 Figure 4. Normalized signals of A) $\mathrm{OH}$-derived $\mathrm{RO}_{2}$ radicals and $\mathbf{B}$ ) $\mathrm{O}_{3}$-derived $\mathrm{RO}_{2}$ radicals 401 produced from the $\mathrm{O}_{3} / \mathrm{OH}+\alpha$-pinene reaction as a function of the ozone concentration. Results 402 obtained by the CI-APi-TOF are given in black and those from the CI-Orbitrap in red using aminium $403\left(\mathrm{n}-\mathrm{C}_{3} \mathrm{H}_{7} \mathrm{NH}_{3}{ }^{+}\right)$ionization in both cases. The Orbitrap data were corrected using the sigmoidal 404 correction function.

405 
A

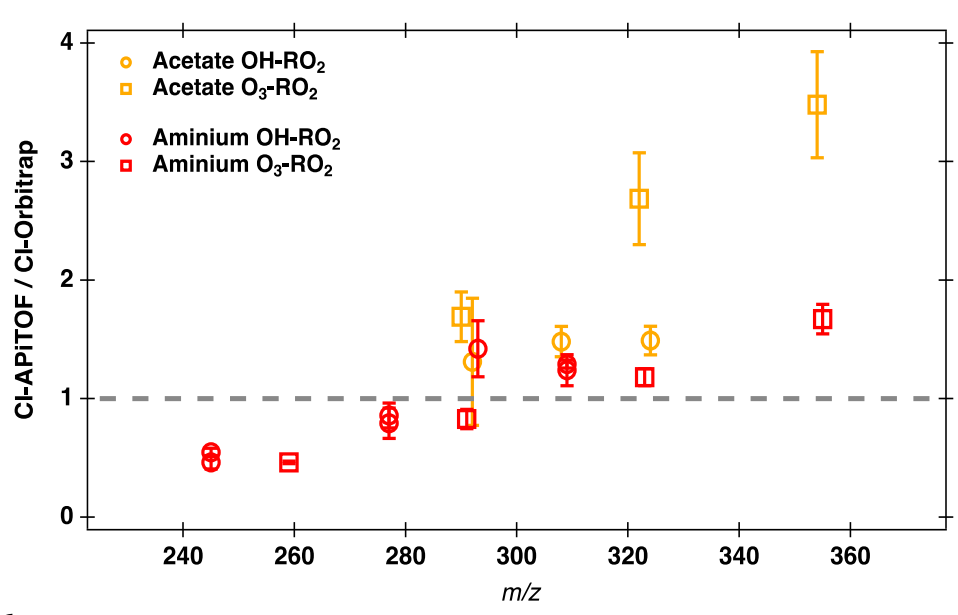

$B$

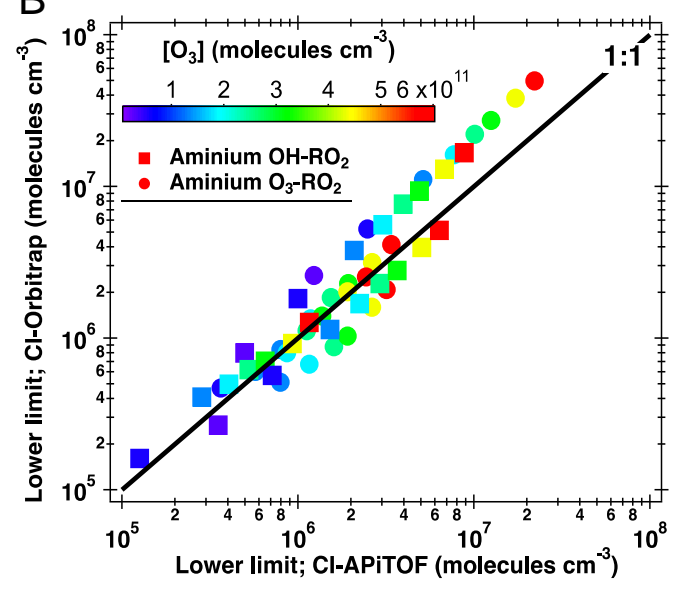

406

407 Figure 5. (A) Comparison between lower limit $\mathrm{RO}_{2}$ radical concentrations measured with the CI-

408 APiTOF and the CI-Orbitrap in the different experiments. (B) Correlation of the concentrations of

$409 \mathrm{RO}_{2}$ radicals formed from the $\mathrm{O}_{3} / \mathrm{OH}+\alpha$-pinene reaction measured by the CI-APi-TOF and the CI-

410 Orbitrap using aminium $\left(\mathrm{n}-\mathrm{C}_{3} \mathrm{H}_{7} \mathrm{NH}_{3}{ }^{+}\right)$ionization. 
A

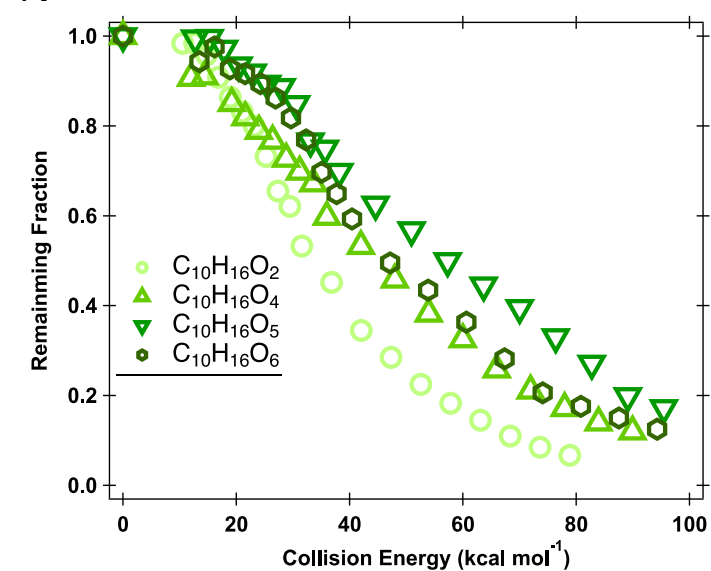

B

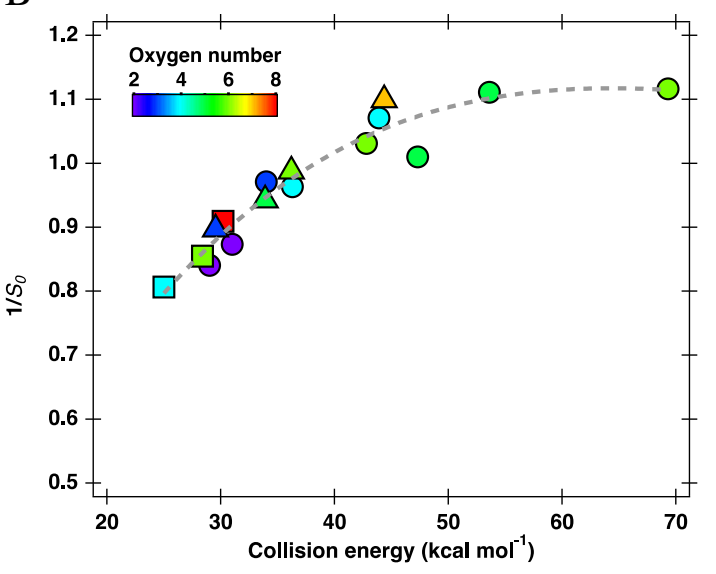

430

431 Figure 6. Declustering scans of $(\mathbf{A}) \mathrm{C}_{10} \mathrm{H}_{16} \mathrm{O}_{2-6}$ measured from the $\mathrm{OH}$-initiated oxidation of $\alpha$-pinene with the CI-Orbitrap using aminium $\left(n-\mathrm{C}_{3} \mathrm{H}_{7} \mathrm{NH}_{3}{ }^{+}\right)$.

(B) Relationship between fitting declustering scans

$434\left(1 / S_{0}\right)$ as a function of collision energy. $\mathrm{CE}_{50}$ is used as a measured of the relative binding energy and 435 corresponds to the collision energy where half of the signal is removed. $S_{0}$ is the maximum amplitude 436 obtained from the sigmoidal fit of declustering scans (e.g., Figure S7) of $\mathrm{RO}_{2}$ radicals (triangle 437 markers) and OVOCs (ON: square markers; non-ON: circle markers) formed from OH-initiated oxidation of $\alpha$-pinene with the CI-Orbitrap using aminium $\left(n-\mathrm{C}_{3} \mathrm{H}_{7} \mathrm{NH}_{3}{ }^{+}\right)$. 
441 Corresponding Authors

$442 *$ E-mail (M. R.): matthieu.riva@ircelyon.univ-lyon1.fr

$443 *$ E-mail (T. B.): berndt@tropos.de

444

445

446

447

448

449

450

451

452

453

454

455

456

457

458

459

460

461

462

463

464

465

466

467

468

469

470

471

472

473

474

475

476

477

478

479

480

481

482

\section{ACKNOWLEDGMENTS}

M.R. wishes to thank the French National program LEFE (Les Enveloppes Fluides et l'Environnement), for their financial support. This research project has received funding from the European Union's Horizon 2020 research and innovation program under grant agreement $N^{\circ} 730997$. The authors wish to thank Frederic Bourgain for technical support.

\section{SUPPORTING INFORMATION}

Figure S1 depicts the schematic of a Q Exactive mass spectrometer. Figure S2 shows the mass spectra of ions at $\mathrm{m} / \mathrm{z} 245$ and 260 measured during the oxidation of $\alpha$-pinene. Figures S3 and S4 present the normalized signals of the organic nitrates and carbonyls produced from the $\mathrm{OH}$-initiated oxidation of $\alpha$-pinene, respectively. Figure S4 shows the correlation of the concentration measured species using both instruments and formed from the $\mathrm{OH}$ radical initiated oxidation of $\alpha$-pinene using acetate-ionbased $\left(\mathrm{CH}_{3} \mathrm{COO}^{-}\right)$ionization. Figure S6 presents the normalized signals of $\mathrm{RO}_{2}$ generated from the oxidation of $\alpha$-pinene measured using aminium $\left(n-\mathrm{C}_{3} \mathrm{H}_{7} \mathrm{NH}_{3}{ }^{+}\right.$). Figure $\mathrm{S} 7$ presents the declustering experiments performed on OVOCs formed from $\alpha$-pinene ozonolysis. Figure S8 shows the mass Spectra of the different perfluorinated acids measured with CI-Orbitrap. Figure S9 presents the relative ion transmission fit determined using the depletion method. The Supporting Information is available free of charge on the ACS Publications website.

\section{REFERENCES}

(1) Hallquist, M.; Wenger, J. C.; Baltensperger, U.; Rudich, Y.; Simpson, D.; Claeys, M.; Dommen, J.; Donahue, N. M.; George, C.; Goldstein, A. H.; Hamilton, J. F.; Herrmann, H.; Hoffmann, T.; Iinuma, Y.; Jang, M.; Jenkin, M. E.; Jimenez, J. L.; Kiendler-Scharr, A.; Maenhaut, W.; McFiggans, G.; Mentel, Th. F.; Monod, A.; Prévôt, A. S. H.; Seinfeld, J. H.; Surratt, J. D.; Szmigielski, R.; Wildt, J. The Formation, Properties and Impact of Secondary Organic Aerosol: Current and Emerging Issues. Atmospheric Chemistry and Physics 2009, 9 (14), 5155-5236. https://doi.org/10.5194/acp-9-5155-2009.

(2) Shrivastava, M.; Cappa, C. D.; Fan, J.; Goldstein, A. H.; Guenther, A. B.; Jimenez, J. L.; Kuang, C.; Laskin, A.; Martin, S. T.; Ng, N. L.; Petaja, T.; Pierce, J. R.; Rasch, P. J.; Roldin, P.; Seinfeld, J. H.; Shilling, J.; Smith, J. N.; Thornton, J. A.; Volkamer, R.; Wang, J.; Worsnop, D. R.; Zaveri, R. A.; Zelenyuk, A.; Zhang, Q. Recent Advances in Understanding Secondary Organic Aerosol: Implications for Global Climate Forcing: Advances in Secondary Organic Aerosol. Reviews of Geophysics 2017, 55 (2), 509-559. https://doi.org/10.1002/2016RG000540.

(3) Wennberg, P. O.; Bates, K. H.; Crounse, J. D.; Dodson, L. G.; McVay, R. C.; Mertens, L. A.; Nguyen, T. B.; Praske, E.; Schwantes, R. H.; Smarte, M. D.; St Clair, J. M.; Teng, A. P.; Zhang, X.; Seinfeld, J. H. Gas-Phase Reactions of Isoprene and Its Major Oxidation Products. Chemical Reviews 
2018. https://doi.org/10.1021/acs.chemrev.7b00439.

(4) Li, H.; Riva, M.; Rantala, P.; Heikkinen, L.; Daellenbach, K.; Krechmer, J. E.; Flaud, P.-M.; Worsnop, D.; Kulmala, M.; Villenave, E.; Perraudin, E.; Ehn, M.; Bianchi, F. Terpenes and Their Oxidation Products in the French Landes Forest: Insights from Vocus PTR-TOF Measurements. Atmos. Chem. Phys. 2020, 20 (4), 1941-1959. https://doi.org/10.5194/acp-20-1941-2020.

(5) Jimenez, J. L.; Canagaratna, M. R.; Donahue, N. M.; Prevot, A. S. H.; Zhang, Q.; Kroll, J. H.; DeCarlo, P. F.; Allan, J. D.; Coe, H.; Ng, N. L.; Aiken, A. C.; Docherty, K. S.; Ulbrich, I. M.; Grieshop, A. P.; Robinson, A. L.; Duplissy, J.; Smith, J. D.; Wilson, K. R.; Lanz, V. A.; Hueglin, C.; Sun, Y. L.; Tian, J.; Laaksonen, A.; Raatikainen, T.; Rautiainen, J.; Vaattovaara, P.; Ehn, M.; Kulmala, M.; Tomlinson, J. M.; Collins, D. R.; Cubison, M. J.; E.; Dunlea, J.; Huffman, J. A.; Onasch, T. B.; Alfarra, M. R.; Williams, P. I.; Bower, K.; Kondo, Y.; Schneider, J.; Drewnick, F.; Borrmann, S.; Weimer, S.; Demerjian, K.; Salcedo, D.; Cottrell, L.; Griffin, R.; Takami, A.; Miyoshi, T.; Hatakeyama, S.; Shimono, A.; Sun, J. Y.; Zhang, Y. M.; Dzepina, K.; Kimmel, J. R.; Sueper, D.; Jayne, J. T.; Herndon, S. C.; Trimborn, A. M.; Williams, L. R.; Wood, E. C.; Middlebrook, A. M.; Kolb, C. E.; Baltensperger, U.; Worsnop, D. R. Evolution of Organic Aerosols in the Atmosphere. Science 2009, 326 (5959), 1525-1529. https://doi.org/10.1126/science.1180353.

(6) Kirkby, J.; Duplissy, J.; Sengupta, K.; Frege, C.; Gordon, H.; Williamson, C.; Heinritzi, M.; Simon, M.; Yan, C.; Almeida, J.; Tröstl, J.; Nieminen, T.; Ortega, I. K.; Wagner, R.; Adamov, A.; Amorim, A.; Bernhammer, A.-K.; Bianchi, F.; Breitenlechner, M.; Brilke, S.; Chen, X.; Craven, J.; Dias, A.; Ehrhart, S.; Flagan, R. C.; Franchin, A.; Fuchs, C.; Guida, R.; Hakala, J.; Hoyle, C. R.; Jokinen, T.; Junninen, H.; Kangasluoma, J.; Kim, J.; Krapf, M.; Kürten, A.; Laaksonen, A.; Lehtipalo, K.; Makhmutov, V.; Mathot, S.; Molteni, U.; Onnela, A.; Peräkylä, O.; Piel, F.; Petäjä, T.; Praplan, A. P.; Pringle, K.; Rap, A.; Richards, N. A. D.; Riipinen, I.; Rissanen, M. P.; Rondo, L.; Sarnela, N.; Schobesberger, S.; Scott, C. E.; Seinfeld, J. H.; Sipilä, M.; Steiner, G.; Stozhkov, Y.; Stratmann, F.; Tomé, A.; Virtanen, A.; Vogel, A. L.; Wagner, A. C.; Wagner, P. E.; Weingartner, E.; Wimmer, D.; Winkler, P. M.; Ye, P.; Zhang, X.; Hansel, A.; Dommen, J.; Donahue, N. M.; Worsnop, D. R.; Baltensperger, U.; Kulmala, M.; Carslaw, K. S.; Curtius, J. Ion-Induced Nucleation of Pure Biogenic Particles. Nature 2016, 533 (7604), 521-526. https://doi.org/10.1038/nature17953.

(7) Ehn, M.; Thornton, J. A.; Kleist, E.; Sipilä, M.; Junninen, H.; Pullinen, I.; Springer, M.; Rubach, F.; Tillmann, R.; Lee, B.; Lopez-Hilfiker, F.; Andres, S.; Acir, I.-H.; Rissanen, M.; Jokinen, T.; Schobesberger, S.; Kangasluoma, J.; Kontkanen, J.; Nieminen, T.; Kurtén, T.; Nielsen, L. B.; Jørgensen, S.; Kjaergaard, H. G.; Canagaratna, M.; Maso, M. D.; Berndt, T.; Petäjä, T.; Wahner, A.; Kerminen, V.-M.; Kulmala, M.; Worsnop, D. R.; Wildt, J.; Mentel, T. F. A Large Source of LowVolatility Secondary Organic Aerosol. Nature 2014, 506 (7489), 476-479. https://doi.org/10.1038/nature13032.

(8) Bianchi, F.; Kurtén, T.; Riva, M.; Mohr, C.; Rissanen, M. P.; Roldin, P.; Berndt, T.; Crounse, J. D.; Wennberg, P. O.; Mentel, T. F.; Wildt, J.; Junninen, H.; Jokinen, T.; Kulmala, M.; Worsnop, D. R.; Thornton, J. A.; Donahue, N.; Kjaergaard, H. G.; Ehn, M. Highly Oxygenated Organic Molecules (HOM) from Gas-Phase Autoxidation Involving Peroxy Radicals: A Key Contributor to Atmospheric Aerosol. Chemical Reviews 2019. https://doi.org/10.1021/acs.chemrev.8b00395.

(9) Crounse, J. D.; Nielsen, L. B.; Jørgensen, S.; Kjaergaard, H. G.; Wennberg, P. O. Autoxidation of Organic Compounds in the Atmosphere. The Journal of Physical Chemistry Letters 2013, 4 (20), 3513-3520. https://doi.org/10.1021/jz4019207.

(10) Berndt, T.; Scholz, W.; Mentler, B.; Fischer, L.; Herrmann, H.; Kulmala, M.; Hansel, A. Accretion Product Formation from Self- and Cross-Reactions of $\mathrm{RO}_{2}$ Radicals in the Atmosphere. Angewandte Chemie International Edition 2018, 57 (14), 3820-3824. https://doi.org/10.1002/anie.201710989. 
(11) Berndt, T.; Richters, S.; Kaethner, R.; Voigtländer, J.; Stratmann, F.; Sipilä, M.; Kulmala, M.; Herrmann, H. Gas-Phase Ozonolysis of Cycloalkenes: Formation of Highly Oxidized $\mathrm{RO}_{2}$ Radicals and Their Reactions with $\mathrm{NO}, \mathrm{NO}_{2}, \mathrm{SO}_{2}$, and Other $\mathrm{RO}_{2}$ Radicals. The Journal of Physical Chemistry A 2015, 119 (41), 10336-10348. https://doi.org/10.1021/acs.jpca.5b07295.

(12) Rissanen, M. P.; Kurtén, T.; Sipilä, M.; Thornton, J. A.; Kangasluoma, J.; Sarnela, N.; Junninen, H.; Jørgensen, S.; Schallhart, S.; Kajos, M. K.; Taipale, R.; Springer, M.; Mentel, T. F.; Ruuskanen, T.; Petäjä, T.; Worsnop, D. R.; Kjaergaard, H. G.; Ehn, M. The Formation of Highly Oxidized Multifunctional Products in the Ozonolysis of Cyclohexene. Journal of the American Chemical Society 2014, 136 (44), 15596-15606. https://doi.org/10.1021/ja507146s.

(13) Jokinen, T.; Sipilä, M.; Richters, S.; Kerminen, V.-M.; Paasonen, P.; Stratmann, F.; Worsnop, D.; Kulmala, M.; Ehn, M.; Herrmann, H.; Berndt, T. Rapid Autoxidation Forms Highly Oxidized RO 2 Radicals in the Atmosphere. Angewandte Chemie International Edition 2014, 53 (52), 14596-14600. https://doi.org/10.1002/anie.201408566.

(14) Jokinen, T.; Berndt, T.; Makkonen, R.; Kerminen, V.-M.; Junninen, H.; Paasonen, P.; Stratmann, F.; Herrmann, H.; Guenther, A. B.; Worsnop, D. R.; Kulmala, M.; Ehn, M.; Sipilä, M. Production of Extremely Low Volatile Organic Compounds from Biogenic Emissions: Measured Yields and Atmospheric Implications. Proceedings of the National Academy of Sciences 2015, 112 (23), 7123-7128. https://doi.org/10.1073/pnas.1423977112.

(15) Wang, S.; Riva, M.; Yan, C.; Ehn, M.; Wang, L. Primary Formation of Highly Oxidized Multifunctional Products in the OH-Initiated Oxidation of Isoprene. A Combined Theoretical and Experimental Study. Environmental Science \& Technology 2018.

https://doi.org/10.1021/acs.est.8b02783.

(16) Ziemann, P. J.; Atkinson, R. Kinetics, Products, and Mechanisms of Secondary Organic Aerosol Formation. Chemical Society Reviews 2012, 41 (19), 6582.

https://doi.org/10.1039/c2cs35122f.

(17) McFiggans, G.; Mentel, T. F.; Wildt, J.; Pullinen, I.; Kang, S.; Kleist, E.; Schmitt, S.; Springer, M.; Tillmann, R.; Wu, C.; Zhao, D.; Hallquist, M.; Faxon, C.; Le Breton, M.; Hallquist, Å. M.; Simpson, D.; Bergström, R.; Jenkin, M. E.; Ehn, M.; Thornton, J. A.; Alfarra, M. R.; Bannan, T. J.; Percival, C. J.; Priestley, M.; Topping, D.; Kiendler-Scharr, A. Secondary Organic Aerosol Reduced by Mixture of Atmospheric Vapours. Nature 2019, 565 (7741), 587-593. https://doi.org/10.1038/s41586-018-0871-y.

(18) Riva, M.; Rantala, P.; Krechmer, J. E.; Peräkylä, O.; Zhang, Y.; Heikkinen, L.; Garmash, O.; Yan, C.; Kulmala, M.; Worsnop, D.; Ehn, M. Evaluating the Performance of Five Different Chemical Ionization Techniques for Detecting Gaseous Oxygenated Organic Species. Atmospheric Measurement Techniques Discussions 2018, 1-39. https://doi.org/10.5194/amt-2018-407.

(19) Krechmer, J.; Lopez-Hilfiker, F.; Koss, A.; Hutterli, M.; Stoermer, C.; Deming, B.; Kimmel, J.; Warneke, C.; Holzinger, R.; Jayne, J. T.; Worsnop, D. R.; Fuhrer, K.; Gonin, M.; de Gouw, J. A. Evaluation of a New Reagent-Ion Source and Focusing Ion-Molecule Reactor for Use in ProtonTransfer-Reaction Mass Spectrometry. Analytical Chemistry 2018. https://doi.org/10.1021/acs.analchem.8b02641.

(20) Breitenlechner, M.; Fischer, L.; Hainer, M.; Heinritzi, M.; Curtius, J.; Hansel, A. PTR3: An Instrument for Studying the Lifecycle of Reactive Organic Carbon in the Atmosphere. Analytical Chemistry 2017, 89 (11), 5824-5831. https://doi.org/10.1021/acs.analchem.6b05110.

(21) Jokinen, T.; Sipilä, M.; Junninen, H.; Ehn, M.; Lönn, G.; Hakala, J.; Petäjä, T.; Mauldin, R. L.; Kulmala, M.; Worsnop, D. R. Atmospheric Sulphuric Acid and Neutral Cluster Measurements 
Using CI-APi-TOF. Atmospheric Chemistry and Physics 2012, 12 (9), 4117-4125.

(22) Lee, B. H.; Lopez-Hilfiker, F. D.; Mohr, C.; Kurtén, T.; Worsnop, D. R.; Thornton, J. A. An Iodide-Adduct High-Resolution Time-of-Flight Chemical-Ionization Mass Spectrometer: Application to Atmospheric Inorganic and Organic Compounds. Environmental Science \& Technology 2014, 48 (11), 6309-6317. https://doi.org/10.1021/es500362a.

(23) Crounse, J. D.; McKinney, K. A.; Kwan, A. J.; Wennberg, P. O. Measurement of Gas-Phase Hydroperoxides by Chemical Ionization Mass Spectrometry. Analytical Chemistry 2006, 78 (19), 6726-6732. https://doi.org/10.1021/ac0604235.

(24) Berndt, T.; Richters, S.; Jokinen, T.; Hyttinen, N.; Kurtén, T.; Otkjær, R. V.; Kjaergaard, H. G.; Stratmann, F.; Herrmann, H.; Sipilä, M.; Kulmala, M.; Ehn, M. Hydroxyl Radical-Induced Formation of Highly Oxidized Organic Compounds. Nat Commun 2016, 7 (1), 13677. https://doi.org/10.1038/ncomms13677.

(25) Berndt, T.; Herrmann, H.; Kurtén, T. Direct Probing of Criegee Intermediates from Gas-Phase Ozonolysis Using Chemical Ionization Mass Spectrometry. Journal of the American Chemical Society 2017, 139 (38), 13387-13392. https://doi.org/10.1021/jacs.7b05849.

(26) Hansel, A.; Scholz, W.; Mentler, B.; Fischer, L.; Berndt, T. Detection of RO 2 Radicals and Other Products from Cyclohexene Ozonolysis with $\mathrm{NH} 4+$ and Acetate Chemical Ionization Mass Spectrometry. Atmospheric Environment 2018, 186, 248-255.

https://doi.org/10.1016/j.atmosenv.2018.04.023.

(27) Cubison, M. J.; Jimenez, J. L. Statistical Precision of the Intensities Retrieved from Constrained Fitting of Overlapping Peaks in High-Resolution Mass Spectra. Atmospheric Measurement Techniques 2015, 8 (6), 2333-2345. https://doi.org/10.5194/amt-8-2333-2015.

(28) Stark, H.; Yatavelli, R. L. N.; Thompson, S. L.; Kimmel, J. R.; Cubison, M. J.; Chhabra, P. S.; Canagaratna, M. R.; Jayne, J. T.; Worsnop, D. R.; Jimenez, J. L. Methods to Extract Molecular and Bulk Chemical Information from Series of Complex Mass Spectra with Limited Mass Resolution. International Journal of Mass Spectrometry 2015, 389, 26-38. https://doi.org/10.1016/j.ijms.2015.08.011.

(29) Zhang, Y.; Peräkylä, O.; Yan, C.; Heikkinen, L.; Äijälä, M.; Daellenbach, K. R.; Zha, Q.; Riva, M.; Garmash, O.; Junninen, H.; Paatero, P.; Worsnop, D.; Ehn, M. A Novel Approach for Simple Statistical Analysis of High-Resolution Mass Spectra. Atmos. Meas. Tech. 2019, 12 (7), 37613776. https://doi.org/10.5194/amt-12-3761-2019.

(30) Riva, M.; Ehn, M.; Li, D.; Tomaz, S.; Bourgain, F.; Perrier, S.; George, C. CI-Orbitrap: An Analytical Instrument To Study Atmospheric Reactive Organic Species. Anal. Chem. 2019, 91 (15), 9419-9423. https://doi.org/10.1021/acs.analchem.9b02093.

(31) Eisele, F. L.; Tanner, D. J. Measurement of the Gas Phase Concentration of $\mathrm{H}_{2} \mathrm{SO}_{4}$ and Methane Sulfonic Acid and Estimates of $\mathrm{H}_{2} \mathrm{SO}_{4}$ Production and Loss in the Atmosphere. Journal of Geophysical Research: Atmospheres 1993, 98 (D5), 9001-9010. https://doi.org/10.1029/93JD00031.

(32) Michalski, A.; Damoc, E.; Hauschild, J.-P.; Lange, O.; Wieghaus, A.; Makarov, A.; Nagaraj, N.; Cox, J.; Mann, M.; Horning, S. Mass Spectrometry-Based Proteomics Using Q Exactive, a HighPerformance Benchtop Quadrupole Orbitrap Mass Spectrometer. Molecular \& Cellular Proteomics 2011, 10 (9), M111.011015. https://doi.org/10.1074/mcp.M111.011015.

(33) Zuth, C.; Vogel, A. L.; Ockenfeld, S.; Huesmann, R.; Hoffmann, T. Ultrahigh-Resolution 
Mass Spectrometry in Real Time: Atmospheric Pressure Chemical Ionization Orbitrap Mass 
(45) Iyer, S.; Lopez-Hilfiker, F.; Lee, B. H.; Thornton, J. A.; Kurtén, T. Modeling the Detection of Organic and Inorganic Compounds Using Iodide-Based Chemical Ionization. The Journal of Physical Chemistry A 2016, 120 (4), 576-587. https://doi.org/10.1021/acs.jpca.5b09837. 